\title{
Design and high temperature behavior of novel heat resistant steels strengthened by high density of stable nanoprecipitates
}

\author{
J. Vivas ${ }^{1 *, 2}$, D. De-Castro ${ }^{1}$, E. Altstadt ${ }^{3}$, M. Houska ${ }^{3}$, D. San-Martín ${ }^{1}$ C. Capdevila ${ }^{1}$ \\ ${ }^{1}$ Materalia Research Group, Physical Metallurgy Department, Centro Nacional de \\ Investigaciones Metalúrgicas (CENIM-CSIC), Avda. Gregorio del Amo 8, 28040 \\ Madrid, Spain. \\ ${ }^{2}$ LORTEK, Ordizia, Guipuzkoa, Spain \\ ${ }^{3}$ Helmholtz-Zentrum Dresden - Rossendorf (HZDR), Dresden, Germany \\ *Corresponding author. \\ E-mail address: jvm@cenim.csic.es (J.Vivas)
}

\begin{abstract}
International efforts have been focused on the development of new $9 \mathrm{Cr}$ Ferritic/Martensitic steels capable of operating at temperatures above $700{ }^{\circ} \mathrm{C}$ to improve thermal efficiency of new power plants. The distribution and size of the MX nanoprecipitates present in these steels have been reported to be the key factor for improving the thermal stability of the microstructure during creep. Bearing in mind these findings, three different heat resistant steels were designed to have a higher number density of MX nanoprecipitates than commercial $9 \mathrm{Cr}$ ferritic/martensitic steels. The manufacturing and subsequent microstructural characterization carried out showed that this goal was achieved. Preliminary high temperature strength results performed by means of Small Punch Creep Tests (SPCT) demonstrated that these new steels improve significantly the high temperature strength without an important loss of ductility as compared to a current commercial 9Cr Ferritic/Martensitic steel.
\end{abstract}

\section{Keywords}

Nanoprecipitates; alloy design; small punch creep tests; high temperature strength; heat resistant steels. 


\section{Introduction}

The maximum operation temperature for commercial $9 \mathrm{Cr}$ heat resistant steels is $620{ }^{\circ} \mathrm{C}$ because at higher temperatures the microstructure becomes thermally unstable $[1,2]$. The microstructure of $9 \mathrm{Cr}$ steels consists in tempered martensite with a high dislocation density. Under creep conditions, the microstructure evolves to form more stable equiaxed ferrite grains. This recovery of the microstructure produces softening by coarsening of laths, packets and blocks [3, 4]. The controlling mechanism for the evolution of the microstructure is the coarsening of two types of precipitates, i.e. $\mathrm{M}_{23} \mathrm{C}_{6}$ and $\mathrm{MX}$ precipitates $[5,6]$. The larger ones are the $\mathrm{M}_{23} \mathrm{C}_{6}$ carbides, rich in $\mathrm{Cr}$, with a phase mole percentage close to $2 \%$ for the commercial G91 ferritic/martensitic steel (Gr.91). They are located on lath, block, packets and prior austenite grain boundaries. Because of their fast coarsening rate during creep, those precipitates have a limited effect on the migration of the grain boundaries [7, 8]. The MX precipitates, which are rich in $\mathrm{V}$ and $\mathrm{Nb}$, are located within the laths with a size ranging from 25 to $50 \mathrm{~nm}$. In contrast to $\mathrm{M}_{23} \mathrm{C}_{6}, \mathrm{MX}$ nanoprecipitates exhibit an excellent thermal stability, acting as obstacles to pin dislocations at high temperature during creep and retarding the microstructural degradation [9-13]. The main concern is the relatively low number density present in the commercial $9 \mathrm{Cr}$ steels. Then, they provide little pinning force and limit the operating temperature of $9 \mathrm{Cr}$ steels.

Many researches have investigated how to raise the number density of MX precipitates. One route is focused on developing alternative processes by thermomechanical treatments [14-18]. The improvement in creep strength recorded in 9Cr ferritic/martensitic steels was related to the high number density of MX nanoprecipitates within the martensitic laths. Indeed, this number density was reported to be up to three orders of magnitude higher than that obtained via conventional heat treatments $[19,20]$. However, the resulting microstructure presents a significant coarse prior austenite grain size with the concomitant loss of creep ductility. Bearing in mind these results, the aim of this work is focused on the development of new heat resistant steels with improved creep strength without ductility loss guided by computational thermodynamic calculations. The microstructural parameter controlling the strength-ductility tradeoff being the number density and distribution of MX precipitates. In fact, this strategy of designing new steels with a high number density of MX nanoprecipitates was introduced previously by Klueh [21] and was applied by Tan et al. for the development of a new generation of RAFM 
steels, named castable nanostructured alloys (CNAs) [22]. Tan et al. showed in their work on CNAs that alloys with a high number density of MX nanoprecipitates can be manufactured using the conventional industrial scale steelmaking method. In addition, they demonstrated that CNAs had superior creep resistance compared to current RAFM steels and justified this improvement based on their enhanced distribution of MX nanoprecipitation [23].

Frequently, one of the main issues when investigating new experimental alloys is the low material availability for testing and the microstructural characterization. For this reason, in this work, the Small Punch Creep technique has been used. This mechanical testing technique allows using miniaturized specimens, discs or sheets with a thin thicknesses [24-28]. Small Punch Creep Tests (SPCT) allow reproducing the characteristic uniaxial creep tests obtaining analogous information i.e. time to rupture or minimum creep rate. It has been employed satisfactorily to evaluate the creep strength of new alloys and welded joints in several works [29-33]. Furthermore, many works have been focused on extrapolating the creep results obtained by means of SPCT to conventional uniaxial creep tests and have highlighted the reliability of this miniaturized specimen testing technique to predict creep strength $[34,35]$. These characteristics make SPCT a very promising and powerful testing technique to be employed as a screening procedure at lab scale for high creep strength alloys.

\section{Experimental procedure}

The Thermo-Calc software has been used to design the alloying system for the new heat resistant steels. All calculations in terms of phase compositions and phase equilibria were carried out with the Thermo-Calc database TCFe8. These steels were designed to contain a High Density of Stable Nanoprecipitates (HDSN); therefore, hereafter they will referred to as HDSN steels.

The compositions of the three steels designed are listed in Table 1. These alloys were produced by vacuum induction melting. The ingots were subjected to a hot-forging plastic deformation of $50 \%$ at $1200{ }^{\circ} \mathrm{C}$ and air cooled to room temperature. Subsequently, they were austenitized for 10 minutes at $1050{ }^{\circ} \mathrm{C}$ followed by air cooling down to room temperature and then tempering for 1 hour at $730{ }^{\circ} \mathrm{C}$ followed by air cooling down to room temperature. 
Table 1. Chemical compositions of the HDSN steels (wt.\%)

\begin{tabular}{|cccccccccc|}
\hline Steel & $\mathrm{Cr}$ & $\mathrm{V}$ & $\mathrm{Nb}$ & $\mathrm{N}$ & $\mathrm{C}$ & $\mathrm{Mo}$ & $\mathrm{W}$ & $\mathrm{Co}$ & $\mathrm{Ni}$ \\
\hline HDSN1 & 8.9 & 0.39 & 0.15 & 0.06 & 0.14 & 0.42 & 1.16 & 1.93 & - \\
\hline HDSN2 & 9.6 & 0.36 & 0.18 & 0.05 & 0.10 & 0.69 & - & - & 1.24 \\
\hline HDSN3 & 8.5 & 0.28 & - & 0.10 & 0.02 & - & 2.42 & 4 & - \\
\hline
\end{tabular}

X-Ray Diffraction (XRD) analysis were carried out with Co- $\mathrm{K}_{\alpha}$ radiation in a Bruker AXS D8 diffractometer to distinguish the phases present in the steels after the heat treatment.

The microstructures of the steels were characterized after the heat treatment and after SPCT by scanning electron microscopy (SEM), transmission electron microscopy (TEM) and by Electron Backscatter Diffraction measurements (EBSD). For the SEM characterization, a scanning electron microscopy model Hitachi S $4800 \mathrm{~J}$ was employed and for the TEM characterization two different microscopes, a JEOL JEM 2100 and a JEOL JEM 3000F, were employed. The EBSD measurements were performed with a JEOL JSM 6500 FEG-SEM. EBSD mapping has been carried out with a step size of 0.1 $\mu \mathrm{m}$. The HKL Channel 5 software has been used for the EBSD data processing.

To prepare the samples for XRD measurements, standard grinding and polishing procedures were used, finishing with a final polish with $1 \mu \mathrm{m}$ diamond paste. In the case of EBSD sample preparation, the residual damage from diamond polishing was removed through an additional polishing stage with a colloidal silica suspension (40 nm).

For the SEM investigations the sample preparation method was the same as that used for the XRD measurements but followed by etching with Vilella's reagent to reveal the microstructural features.

TEM samples were prepared with disks of $3 \mathrm{~mm}$ in diameter and $100 \mu \mathrm{m}$ in thickness. The thickness of these slices were further mechanically thinned and, afterwards, twin-jet electropolishing was performed at $25{ }^{\circ} \mathrm{C}$ and $40 \mathrm{~V}$ using an electrolyte compose of $95 \%$ acetic acid and $5 \%$ percloric acid.

The equivalent circle diameter of the particles was calculated with an image editor (ImageJ) to carry out a quantitative analysis of the size and number density of precipitates. For the $\mathrm{M}_{23} \mathrm{C}_{6}$ precipitates analysis, SEM micrographs were used; while for MX nanoprecipitates, TEM micrographs were employed. More than 100 particles were analyzed for each kind of precipitate. 
The SPCTs were carried out at a constant temperature of $700{ }^{\circ} \mathrm{C}$ with a load of $275 \mathrm{~N}$ in a controlled atmosphere of argon to obtain information on the creep behavior of the developed steels. SPCT samples were cut transversally, from cylindrical specimens, with a thickness of $600 \mu \mathrm{m}$ and a diameter of $8 \mathrm{~mm}$. Then, the discs were ground on both sides down to a final thickness of $500 \mu \mathrm{m}$. In the set-up of the SPCT, the lower and upper die are connected via a thread to ensure the clamping of the sample. The load is applied by a $\mathrm{Al}_{2} \mathrm{O}_{3}$ punch ball which is in contact with the sample. A plunger rod made of Mo is used to transmit the dead weight load to the punch ball. The clamping device is surrounded by an electrical heater and a thermal insulation. The upper plate carrying the additional dead weight is guided by two pillars with ball-bearings. The temperature is measured in the lower die directly under the sample. The displacement is measured by a capacitive sensor between the upper plate and the thermal insulation with an accuracy of $\pm 1 \mu \mathrm{m}$. A load cell is placed between upper plate and plunger rod.

The upper plate with the dead weight can be locked by an electric spindle. This enables the start of the loading of the sample after heating-up and reaching the thermal equilibrium of the set-up. The experimental set-up is completely covered by an air-tight shell which is evacuated and flooded with Ar prior to the test. All SPC tests were performed in an Ar atmosphere with a nominal constant force resulting from the dead weight. The loading of the sample started after Ar flooding and heating-up.

\section{Results and discussion}

\subsection{Steel design}

The new steels produced, the so-called High Density of Stable Nanoprecipitates (HDSN) steels, were designed to have a higher amount of MX nanoprecipitates compared with 9Cr conventional ferritic/martensitic steels. Bearing in mind the beneficial aspects of those nanoprecipitates reported above, different alloying elements were added to reach this target and implement the design strategy to strengthen the steel at high temperature as it is explained below.

Cr-content: A value of $9 \mathrm{wt} . \% \mathrm{Cr}$ was fixed since according to the literature this value guarantees the oxidation resistance at high temperature $\left(650-700{ }^{\circ} \mathrm{C}\right) . \mathrm{Cr}$ favors the precipitation of $\mathrm{M}_{23} \mathrm{C}_{6}$ carbides, which retard the microstructural degradation during creep by pinning of the lath, block and grain boundaries [36]. 
Mo and $\mathrm{W}$ content: The addition of elements such as $\mathrm{W}$ and Mo is carried out to provide solid solution strengthening, which leads to higher creep strength at elevated operating temperatures. Besides, the $\mathrm{W}$ and Mo retard the recovery of martensitic laths by decreasing the self-diffusion rate [37]. By contrast, W and Mo promote the Laves phase formation, which possesses a poor thermal stability and coarsen quickly $[38,39]$. However, some researchers have reported that this phase is able to increase creep strength by lath boundary pinning before coarsening [40].

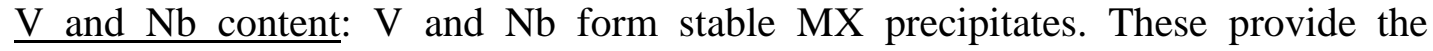
precipitation strengthening necessary to pin the dislocations during creep and extend the time to rupture[41, 42].

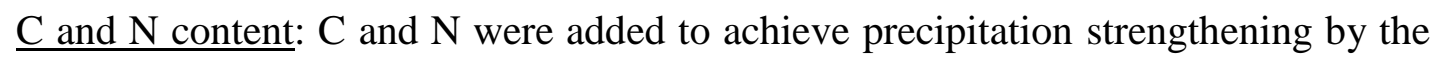
formation of $\mathrm{M}_{23} \mathrm{C}_{6}$ carbides and $\mathrm{MX}$ precipitates. High contents of $\mathrm{C}$ and $\mathrm{N}$ must be avoided to facilitate the weldability $[43,44]$.

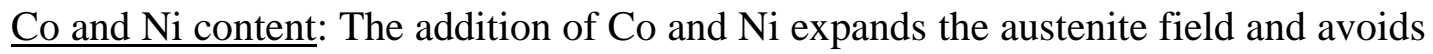
the formation of delta ferrite during the austenitization heat treatment $[45,46]$.

The three HDSN steels have been developed to be an evolution of the conventional Grade 92 and Grade 91 9Cr steels. All HDSN steels were designed to have a ferritic matrix strengthened by several precipitates, but different strategies were adopted for each design to control the chemical composition of the ferritic matrix and the distribution and composition of the precipitates.

The HDSN1 and HDSN2 steels were designed to be strengthened by MX nanocarbonitrides. The addition of high amounts of $\mathrm{Nb}, \mathrm{V}, \mathrm{C}$ and $\mathrm{N}$ favors the formation of this type of nanoprecipitates. In addition to these elements, solid solution strengthening was implemented by the addition of Mo and W to HDSN1 steel and only Mo to HDSN2 steel. Because these elements, together with $\mathrm{V}$ and $\mathrm{Nb}$, are strong ferrite stabilizers, Co was added in HDSN1 steel and Ni in HDSN2 steel to widen the austenite phase field and avoid the formation of delta ferrite during the austenitization heat treatment. Delta ferrite has been reported to reduce the creep strength in high Cr heat resistant steels [46].

Figure 1 shows the phase mole percentage of precipitates present in the HDSN1 and HDSN2 steels compared to a conventional 9Cr steels (G91) after tempering at $730{ }^{\circ} \mathrm{C}$ and reaching equilibrium conditions. The increase in MX precipitates is clear in the HDSN steels compared to G91. The slightly higher amount of MX precipitates in HDSN1 steel compared to HDSN2 steel is because of its higher $\mathrm{C}$ and $\mathrm{N}$ contents. Note that the higher $\mathrm{C}$ content promotes the formation of a higher amount of $\mathrm{M}_{23} \mathrm{C}_{6}$ carbides as well. 


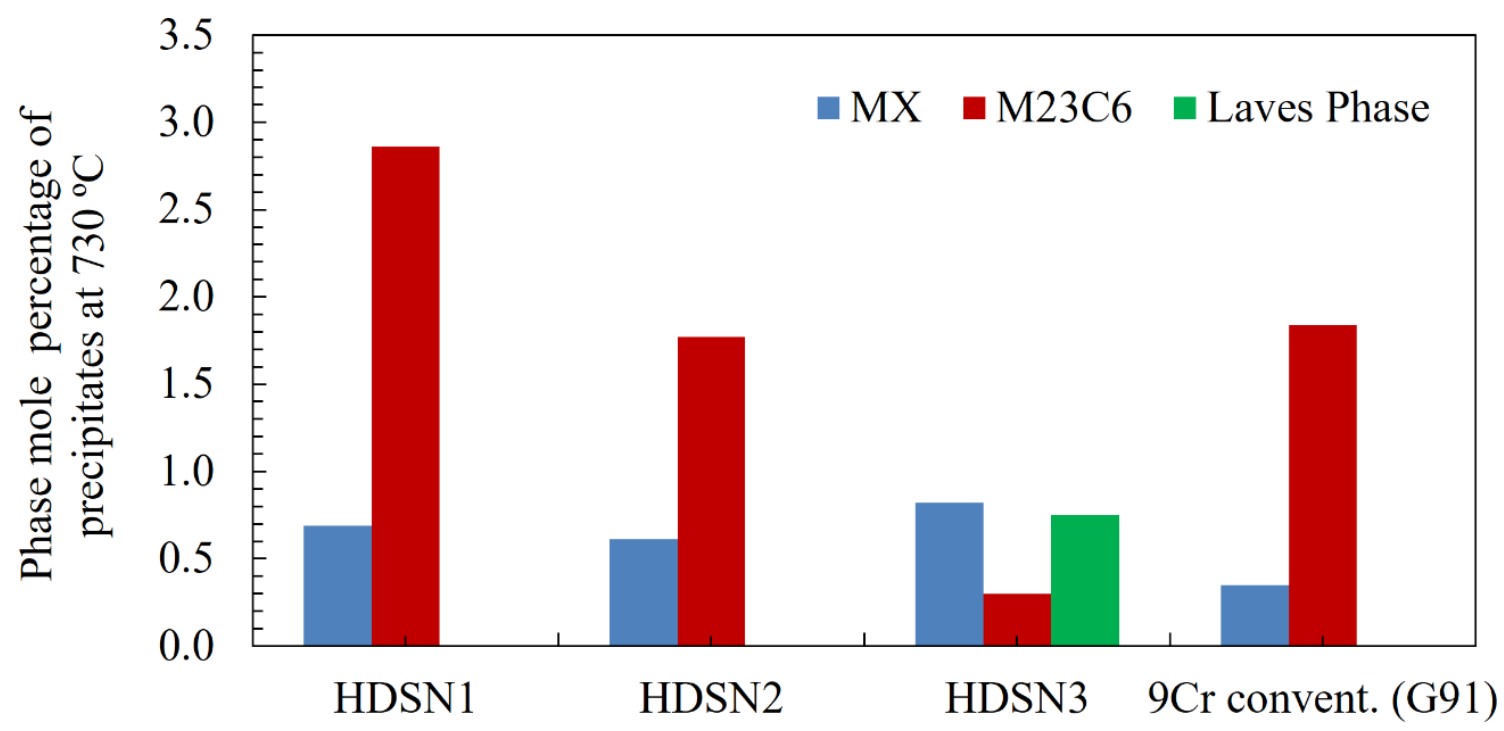

Figure 1. Thermo-Calc equilibrium calculations of the phase mole percentage for the MX, $\mathrm{M}_{23} \mathrm{C}_{6}$ and the Laves Phase precipitates in the HDSN and G91 steels after tempering at $730{ }^{\circ} \mathrm{C}$.

In contrast to HDSN1 and HDSN2 steels, the HDSN3 steel was designed to possess a higher population of MX nanonitrides. To achieve this, the $\mathrm{C}$ content was reduced down to $0.02 \mathrm{wt} . \%$ and the $\mathrm{N}$ content increased up to $0.10 \mathrm{wt} . \%$. Figure 1 shows that the amount of MX nitrides predicted by Thermo-Calc for HDSN3 steel is considerably higher than that predicted for HDSN1 and HDSN2 steels and, of course, for G91 steel. In addition, this reduction in $\mathrm{C}$ leads to a considerable reduction of the amount of $\mathrm{M}_{23} \mathrm{C}_{6}$ carbides. It is worth noting that $\mathrm{Nb}$ was not added to this steel with the aim of investigating the lack of this element on the long-term creep stability of MX precipitates. Then, the MX precipitates used for the strengthening of this steel are V-nanonitrides in contrast to the previous designs, i.e. HDSN1 and HDSN2 steels, where MX precipitates were designed to be of the type $(\mathrm{V}, \mathrm{Nb})(\mathrm{C}, \mathrm{N})$. Furthermore, as in the HDSN1 steel, W was added for solid solution strengthening and Co to prevent delta ferrite formation. The higher $\mathrm{W}$ content for this steel, compared to the HDSN1 steel, promotes the formation of Laves Phase, at the tempering temperature (Figure 1), along with $\mathrm{M}_{23} \mathrm{C}_{6}$ carbides.

It is noteworthy that MX precipitates, i.e. $(\mathrm{V}, \mathrm{Nb})(\mathrm{C}, \mathrm{N})$, dissolve during creep and allow for the formation of the $\mathrm{Z}$ phase, i.e. $\mathrm{Cr}(\mathrm{V}, \mathrm{Nb})(\mathrm{C}, \mathrm{N})$, at very long creep exposure times [47-49]. These latter precipitates show a lower thermal stability and its precipitation strengthening is limited to short creep times. The previous calculations made by ThermoCalc were performed without considering the formation of $\mathrm{Z}$ phase due to this paper being 
focused on the creep strength of the initial microstructure, i.e. at short creep exposure times. However, an evaluation of the fraction of $\mathrm{Z}$ phase might be considered as a broad approach regarding the influence of this phase on the long-term creep strength. In this sense, Figure 2 shows the phase mole percentage of $\mathrm{Z}$ phase and MX precipitates predicted for the HDSN steels at an operation temperature of $700{ }^{\circ} \mathrm{C}$.

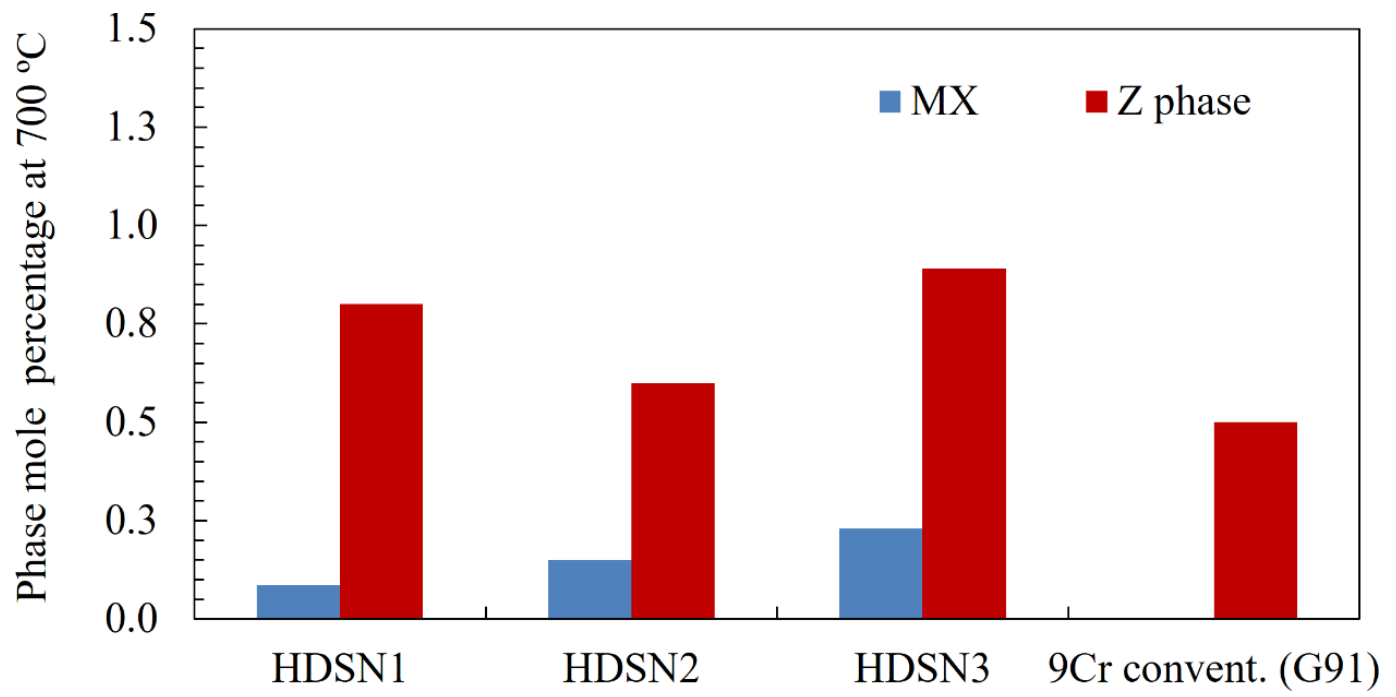

Figure 2. Thermo-Calc equilibrium calculations of phase mole percentage for the MX precipitates and Z phase in the HDSN and G91 steels at the operation temperature of $700{ }^{\circ} \mathrm{C}$.

As it can be deduced, after comparing Figure 1 and Figure 2, the amount of MX precipitates is drastically reduced for all HDSN and G91 steels. This fact, together with the presence of $\mathrm{Z}$ phase for all steels, would result in a drop in the creep strength. The G91, HDSN1 and HDSN3 would be the steels with the most important loss of creep strength at long creep exposure times due to the great drop in the amount of MX nanoprecipitates and the increase in the $\mathrm{Z}$ phase formation. In the case of HDSN2 steel, this drop in MX precipitates and increase in the $\mathrm{Z}$ phase are less pronounced and, in consequence, an inferior loss in creep strength could be expected. Nevertheless it should be bore in mind that this analysis does not take into account the size and distribution of the MX and Z-phase in the three steels at long creep times. These factors have also an important influence on the creep strength in addition to the mole percentage provided in Figure 2. 


\subsection{Characterization of the initial microstructure}

Figure 3 shows the XRD patterns of the tempered HDSN steels. For all of them, the major phase has a bcc crystalline structure. This fact is in good agreement with Thermo-Calc simulations, where ferrite is predicted as the phase with the highest mole fraction for all designed steels. It can be seen that the HDSN1 and HDSN2 steels show identifiable peaks associated with the presence of $\mathrm{M}_{23} \mathrm{C}_{6}$ carbides. Additionally, the peaks around $2 \theta=40^{\circ}$ correspond to the MX precipitates. 

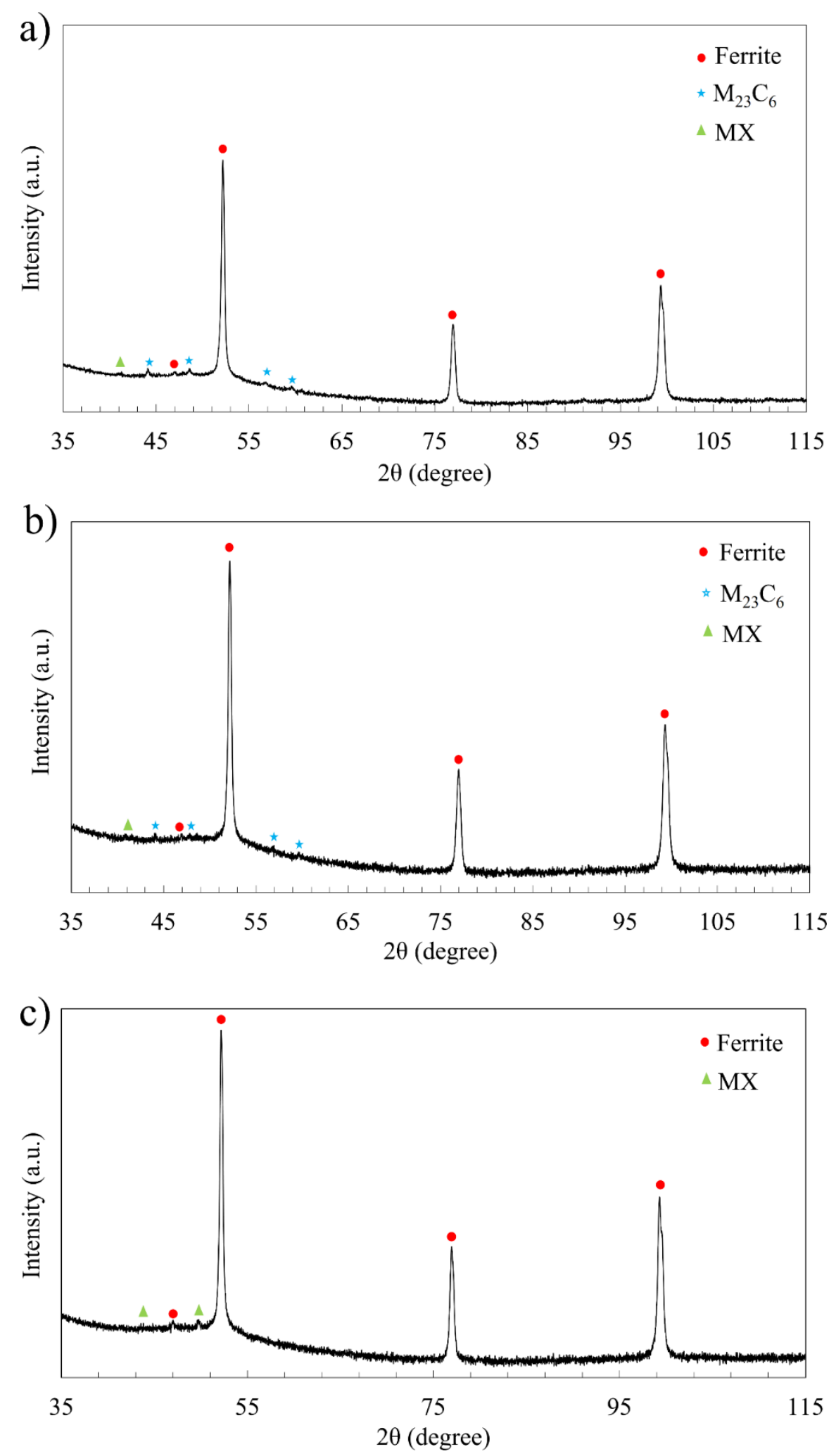

Figure 3. XRD patterns obtained for a) HDSN1, b) HDSN2 and c) HDSN3 steels after the heat treatments $\left(1050{ }^{\circ} \mathrm{C}-10 \mathrm{~min}+\right.$ quenching to room temperature $+730{ }^{\circ} \mathrm{C}-1 \mathrm{~h}+$ quenching to room temperature). 
It is worth mentioning that no peaks were detected for the $\mathrm{M}_{23} \mathrm{C}_{6}$ carbides or the Laves Phase in the HDSN3 steel, only the peaks due to the MX precipitates were observed around $2 \theta=40-50^{\circ}$. The lack of $\mathrm{M}_{23} \mathrm{C}_{6}$ carbides peaks can be explained based on the expected low amount of these carbides, which would be due to the low carbon content of the steel, which limits their detection by XRD. The lack of the Laves phase peaks could be attributed to the short tempering time (60 $\mathrm{min})$, which was not long enough to promote the nucleation of this phase [50]. Previous works have shown that the Laves phase takes a long time to nucleate in $9 \mathrm{Cr}$ ferritic/martensitic steels and it usually takes place during creep [51].

Figure 4 shows the Inverse Pole Figure (IPF) maps for the HDSN steels after the heat treatments. All of them present the typical martensitic microstructure with its characteristic lath-like shape morphology. The ferritic matrix contains a high density of interfaces such as prior austenite grain boundaries, lath boundaries and block boundaries. The high density of interfaces is due to the martensitic microstructure, which forms after cooling from the austenitization temperature. The precipitation of the different creep strengthening precipitates occurs during tempering. 

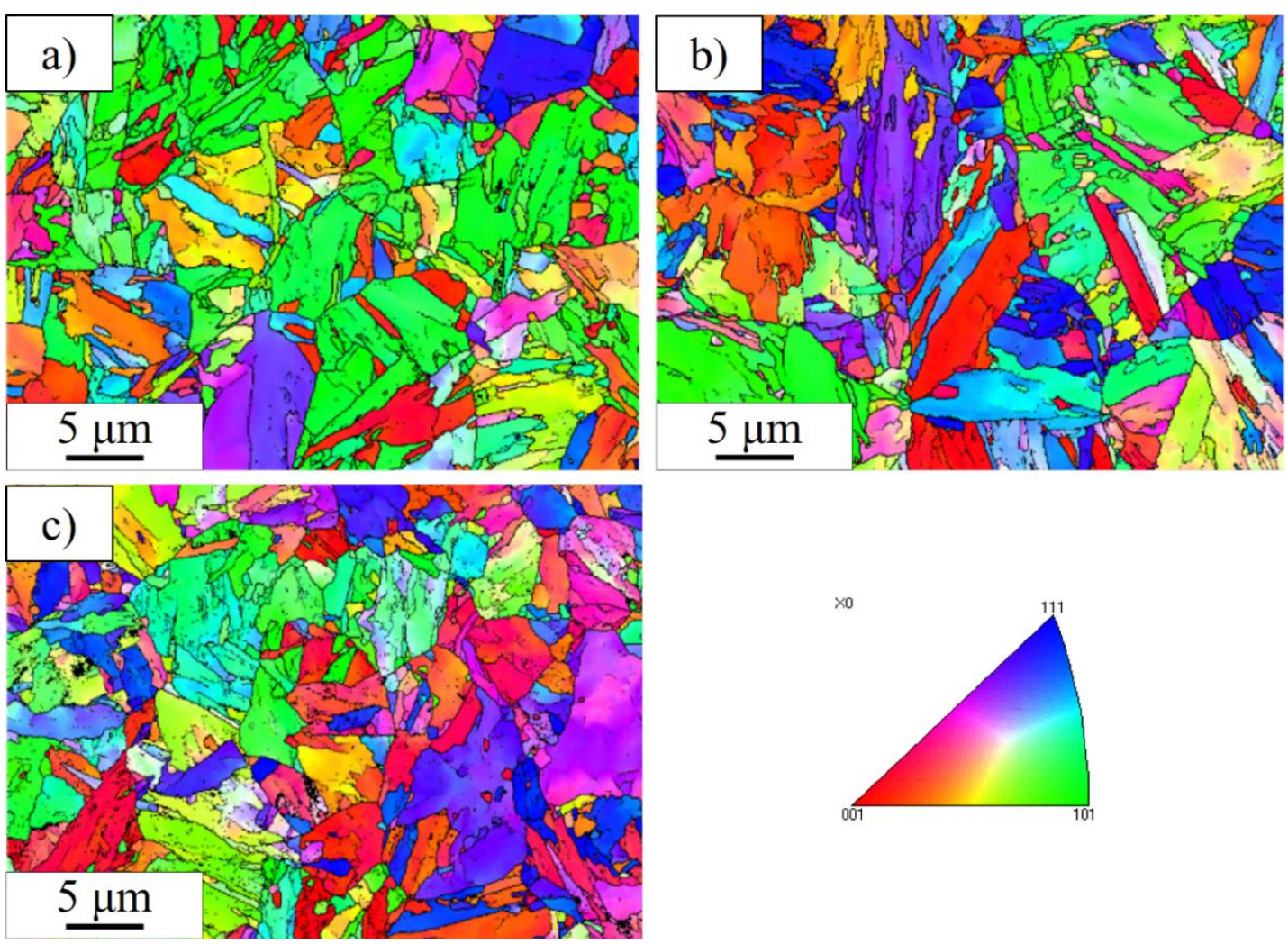

Figure 4. IPF maps of the martensitic microstructure after heat treatment $\left(1050^{\circ} \mathrm{C}-10 \mathrm{~min}\right.$ + quenching to room temperature $+730^{\circ} \mathrm{C}-1 \mathrm{~h}+$ quenching to room temperature) for a) HDSN1; b) HDSN2 and c) HDSN3 steels.

Figure 5a) and Figure 6a) allow us to observe the $\mathrm{M}_{23} \mathrm{C}_{6}$ carbide distribution for the HDSN1 and HDSN2 steels, respectively. They are located on prior austenite grain boundaries, block boundaries and lath boundaries with a rod shape. The Energydispersive X-ray Spectroscopy analysis (EDX) carried out in these precipitates, shown in Figure $5 \mathrm{~b}$ ) and Figure $6 \mathrm{~b}$ ), indicate that the $\mathrm{M}_{23} \mathrm{C}_{6}$ carbides found in HDSN1 steel are rich in $\mathrm{Cr}, \mathrm{W}$ and Mo, while those in HDSN2 are rich in $\mathrm{Cr}$ and Mo. The compositions of these precipitates are consistent with the thermodynamic calculations. 

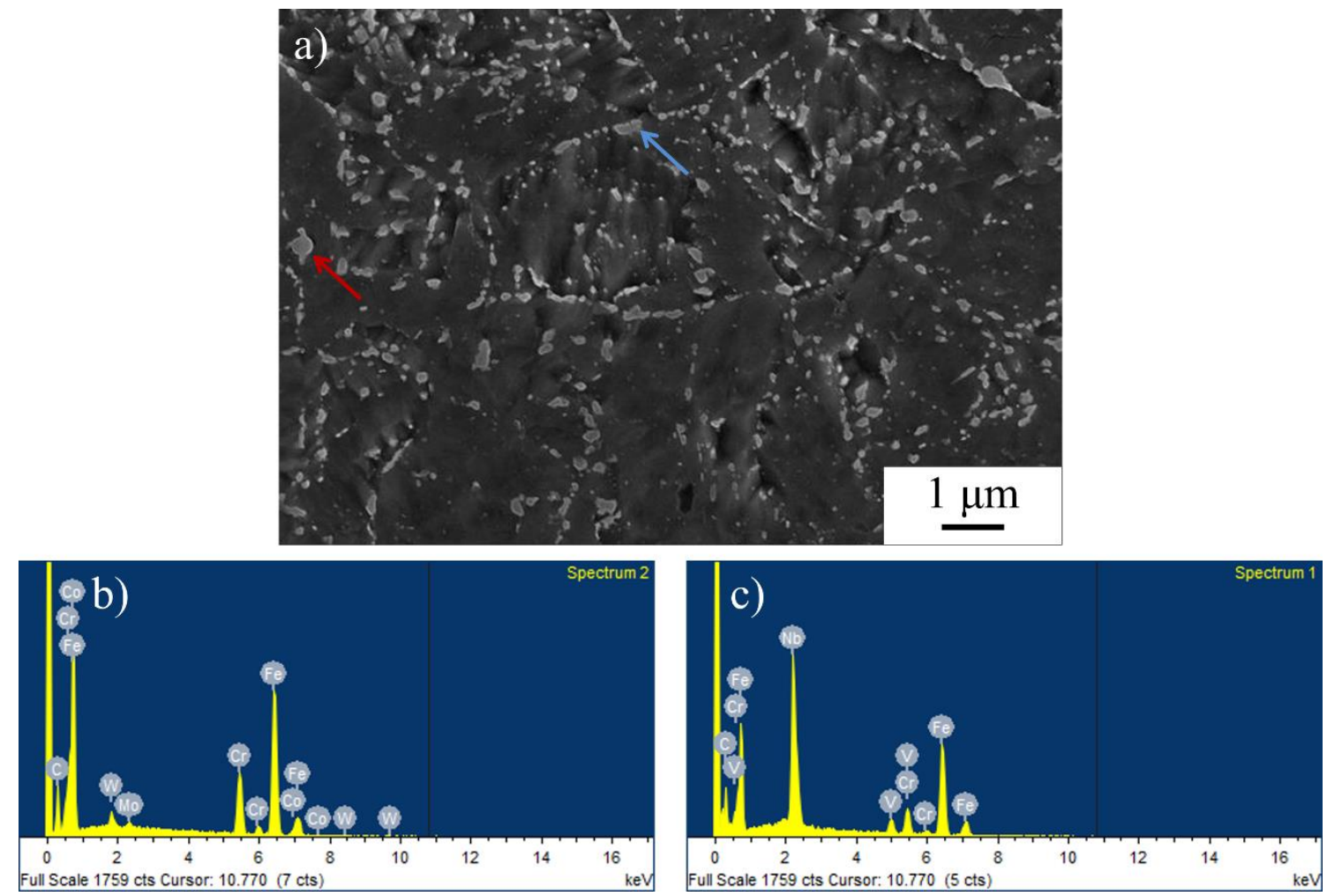

Figure 5. a) SEM micrograph of the HDSN1 steel microstructure after the tempering treatment; b) EDX from the precipitate indicated by the blue arrow in a) and c) EDX from the precipitate indicated by the red arrow in a). 

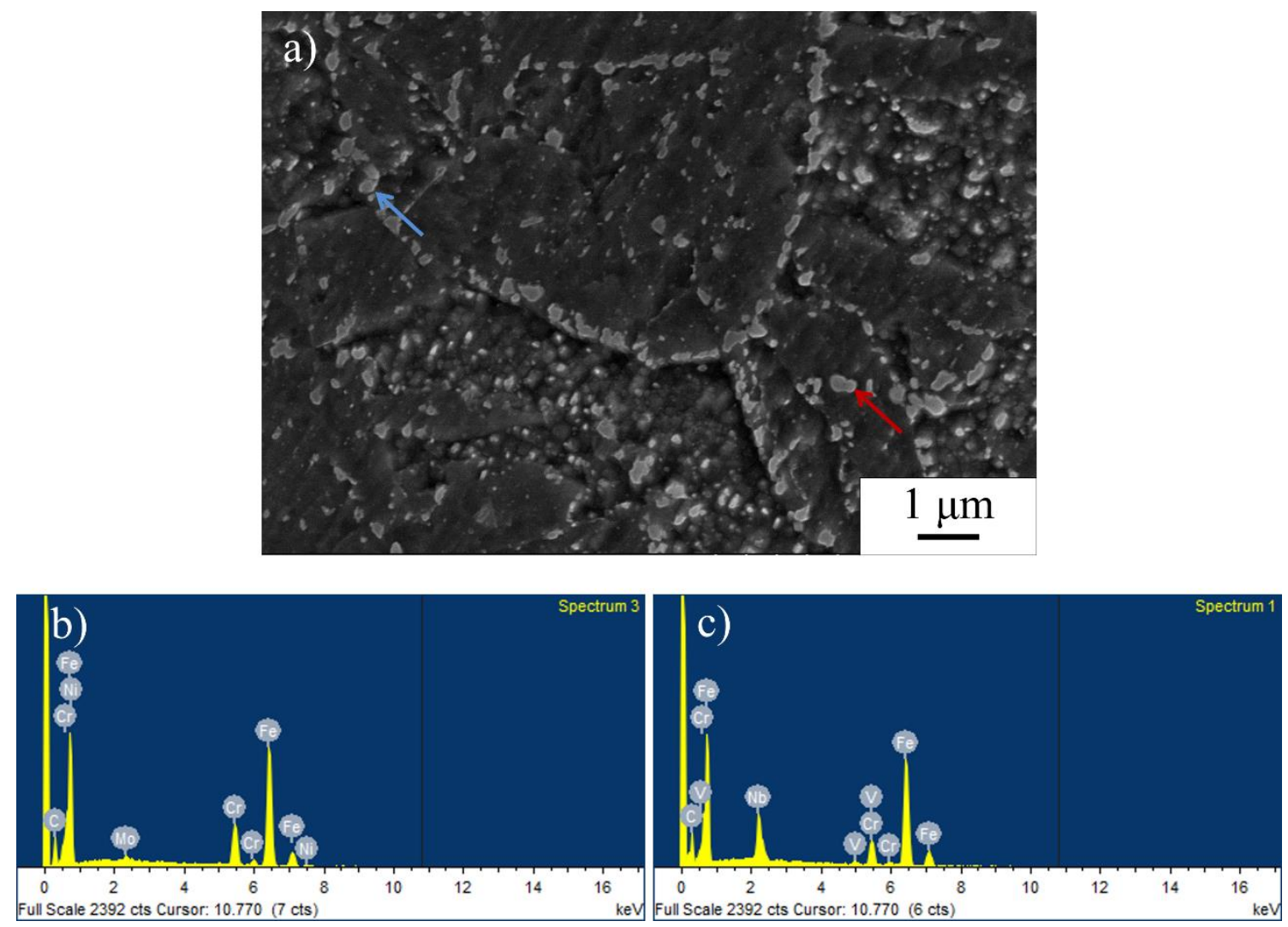

Figure 6. a) SEM micrograph of the HDSN2 steel microstructure after the tempering treatment; b) EDX from the precipitates indicated by the blue arrow in a) and c) EDX from the precipitate indicated by the red arrow in a).

Some MX-precipitates (Figure 5a) and Figure 6a)), which were not dissolved during the austenitization, the so-called primary carbides, were observed in HDSN1 and HDSN2 steels. These precipitates have a spheroidal shape and are rich in $\mathrm{Nb}$ as it is demonstrated by the EDX in Figure 5c) and Figure 6c) for HDSN1 and HDSN2 steels, respectively.

Figure 7 shows the distribution of precipitates in the HDSN3 steel. These precipitates were found to be rich in $\mathrm{V}$. The enrichment in $\mathrm{V}$ allows deducing that these precipitates are of the type V-MX. Precipitates rich in Cr or W of the type $\mathrm{M}_{23} \mathrm{C}_{6}$ carbides or the Laves Phase were not observed. 

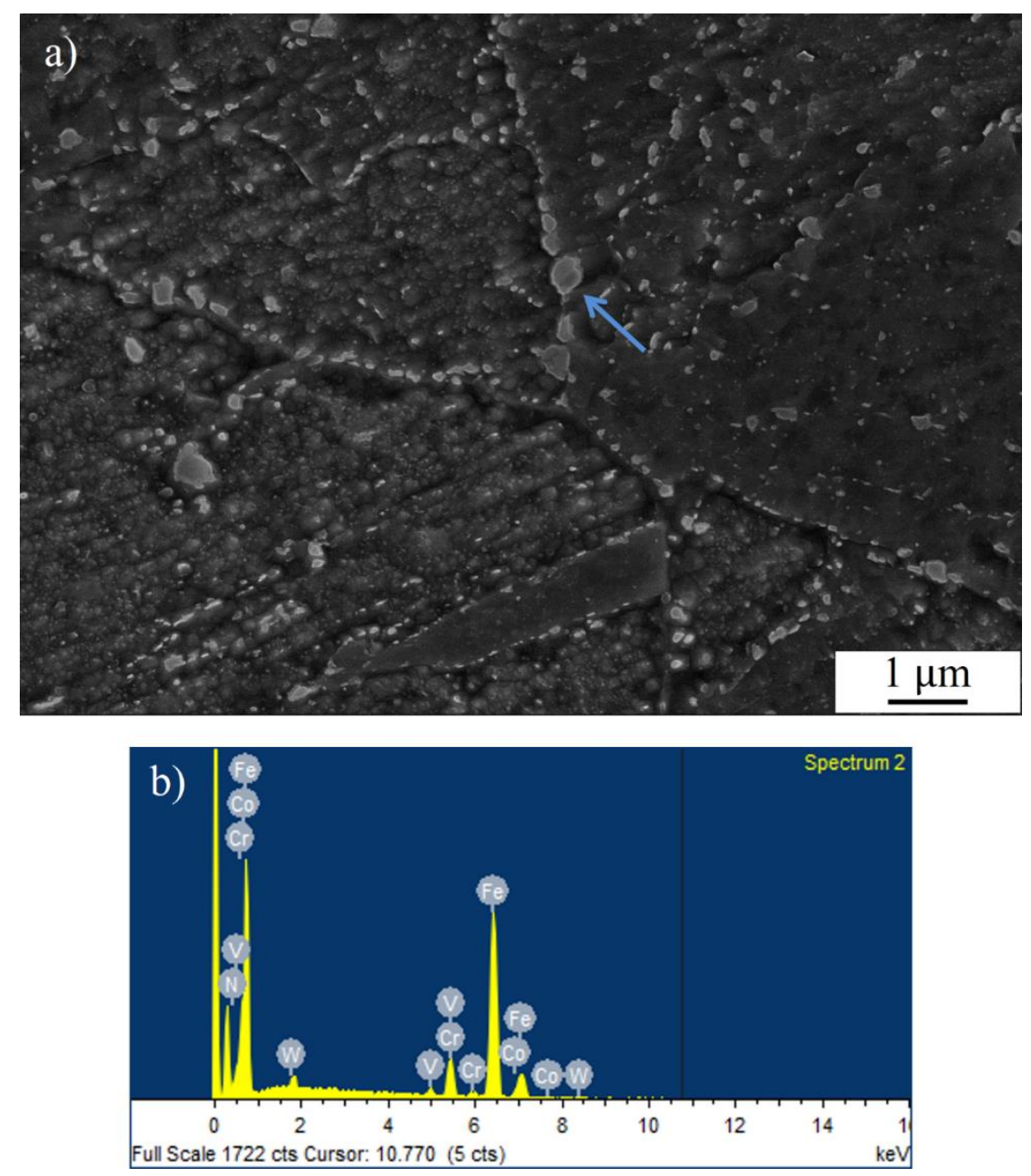

Figure 7. a) SEM micrograph of the HDSN3 steel microstructure after the tempering treatment; b) EDX from the precipitate indicated by the blue arrow in a).

Figure 8 shows TEM micrographs for HDSN1 and HDSN2 steels to disclose the distribution of the MX nanoprecipitates. While $\mathrm{M}_{23} \mathrm{C}_{6}$ carbides are located on block and lath boundaries, MX nanoprecipitates appear located within the laths. 

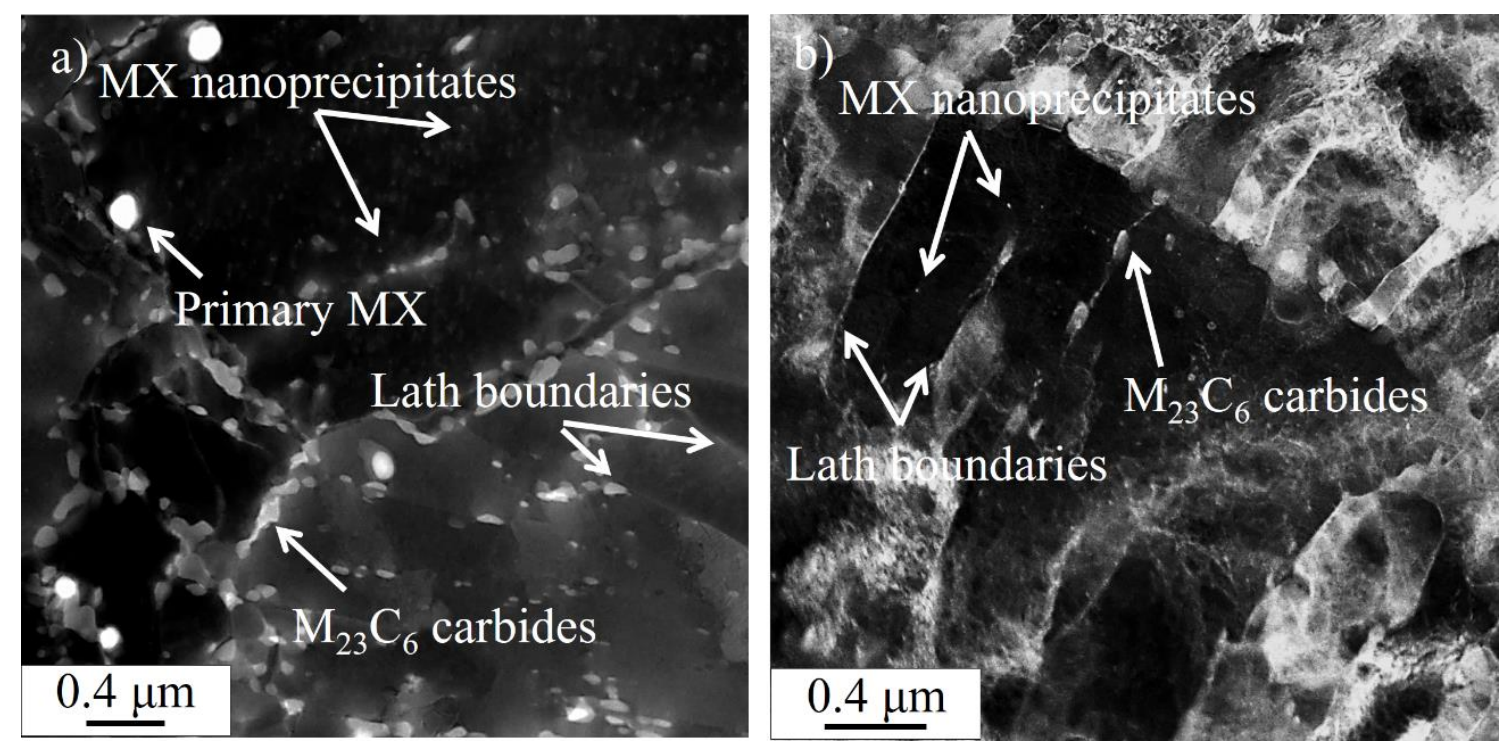

Figure 8. TEM micrographs of the microstructure of a) HDSN1 and b) HDSN2 steels after the tempering treatment. White arrows indicate different kinds of precipitates and lath boundaries.

Figure 9 shows a detail of the distribution and size of MX nanoprecipitates found in HDSN1 and HDSN2 steels.
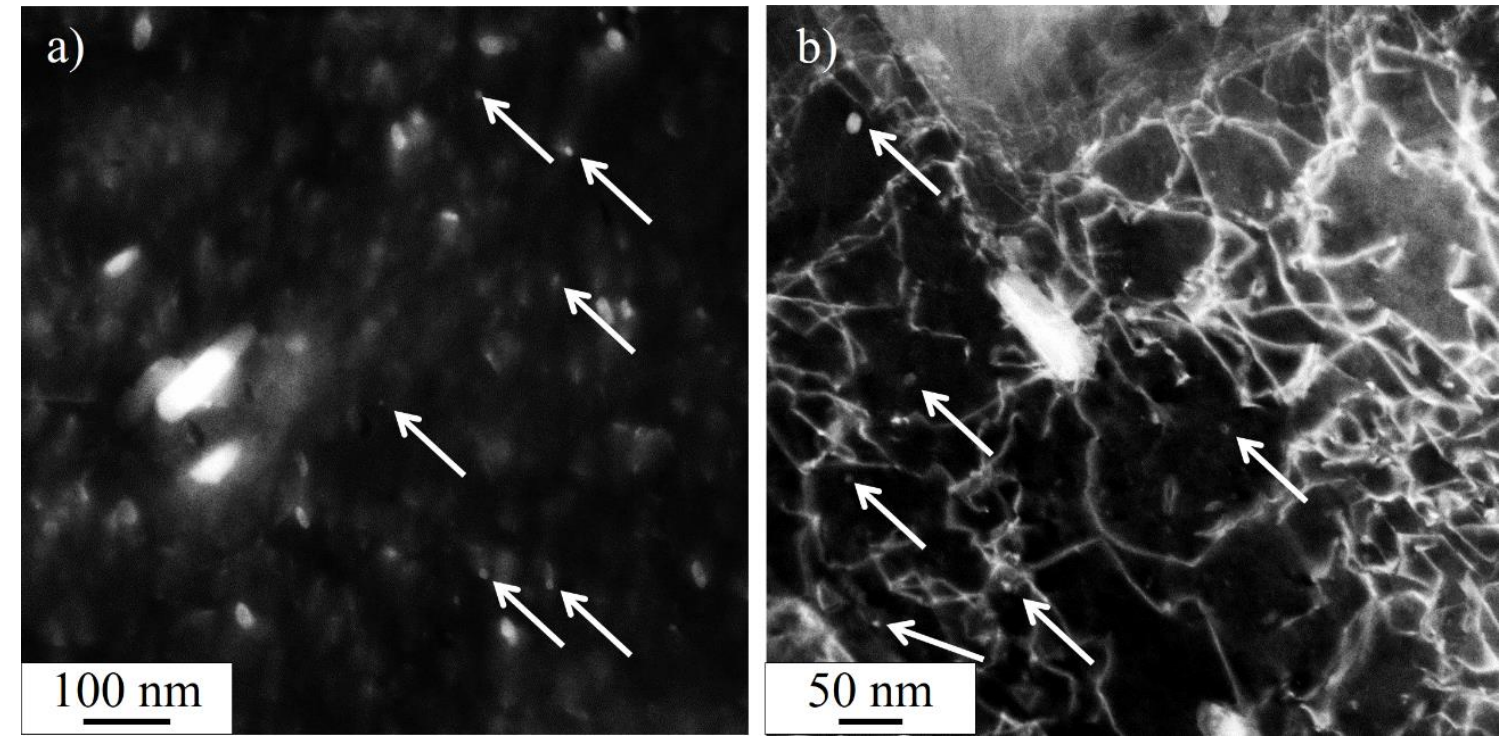

Figure 9. TEM micrographs showing the presence of MX nanoprecipitates distributed within the laths in a) HDSN1 and b) HDSN2 steels after the tempering treatment. Some MX nanoprecipitates have been pointed out by white arrows. 
Regarding HDSN3 steel, fine MX nanoprecipitates are also observed within the laths (Figure 10) in a high number density. Note that these MX nanoprecipitates are smaller than those located on prior austenite, block and lath boundaries (Figure 7). While the size of MX nanoprecipitates observed within the laths are ranging from 10-30 nm, the MX precipitates located on prior austenite, block and lath boundaries are larger than $100 \mathrm{~nm}$.

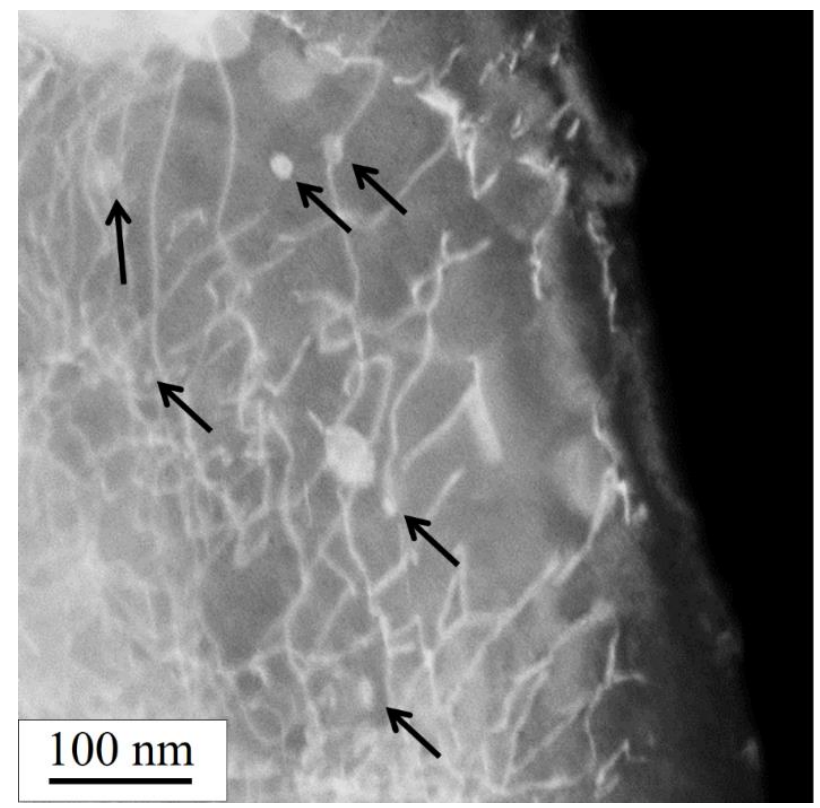

Figure 10. TEM micrograph of the microstructure of the HDSN3 steel showing the distribution of MX nanoprecipitates within the laths. Some of MX nanoprecipitates have been pointed out by black arrows.

Because of the small size of the MX nanoprecipitates present in the HDSN steels, an EDX analysis by TEM is not effective to obtain their compositions properly. Future work is needed to study the nature and the chemical compositions of these nanoprecipitates, which are thought to play a key role in the creep behavior of HDSN steels.

To quantify the effect of the different strategies followed in the design of these HDSN steels on the creep strengthening ability of the precipitates, the number density and average particle size of $\mathrm{M}_{23} \mathrm{C}_{6}$ carbides and $\mathrm{MX}$ nanoprecipitates have been measured and are displayed in

Table 2. 
Table 2. Number density and mean size of $\mathrm{M}_{23} \mathrm{C}_{6}$ carbides and $\mathrm{MX}$ nanoprecipitates observed in the HDSN steels.

\begin{tabular}{|c|c|c|c|c|c|c|}
\cline { 2 - 7 } \multicolumn{2}{c|}{} & \multicolumn{2}{c|}{ HDSN1 } & \multicolumn{2}{c|}{ HDSN2 } & \multicolumn{2}{c|}{ HDSN3 } \\
\cline { 2 - 7 } & $\begin{array}{c}\text { Size } \\
(\mathrm{nm})\end{array}$ & $\begin{array}{c}\text { Number } \\
\text { density } \\
\left(\mathrm{m}^{-3}\right)\end{array}$ & $\begin{array}{c}\text { Size } \\
(\mathrm{nm})\end{array}$ & $\begin{array}{c}\text { Number } \\
\text { density } \\
\left(\mathrm{m}^{-3}\right)\end{array}$ & $\begin{array}{c}\text { Size } \\
(\mathrm{nm})\end{array}$ & $\begin{array}{c}\text { Number } \\
\text { density } \\
\left(\mathrm{m}^{-3}\right)\end{array}$ \\
\hline $\mathrm{M}_{23} \mathrm{C}_{6}$ & $132 \pm 4$ & $7.48 \cdot 10^{19}$ & $107 \pm 5$ & $8.22 \cdot 10^{19}$ & - & - \\
\hline $\mathrm{MX}$ & $11 \pm 2$ & $1.60 \cdot 10^{22}$ & $9 \pm 1$ & $2.23 \cdot 10^{22}$ & $80 \pm 3$ & $3.34 \cdot 10^{20}$ \\
\hline
\end{tabular}

The HDSN1 and HDSN2 steels display very similar number density and average particle size for $\mathrm{M}_{23} \mathrm{C}_{6}$ carbides and $\mathrm{MX}$ nanoprecipitates. These results are in good agreement with the thermodynamic prediction where slightly higher mole fractions of $\mathrm{M}_{23} \mathrm{C}_{6}$ and MX precipitates were predicted for the HDSN1 steel and, in consequence, no important changes in the number density and size of the precipitates were expected. In the HDSN3 steel, the number density of MX precipitates measured was higher compared to those observed for the $\mathrm{M}_{23} \mathrm{C}_{6}$ carbides in the HDSN1 and HDSN2 steels. However, the number density of these MX nanoprecipitates for the HDSN3 steel is smaller than that measured for the HDSN1 and HDSN2 steels. This observation is explained by the different nucleation sites employed by the MX precipitates in the HDSN1 and HDSN2 steels compared to the HDSN3 steel. The MX nanoprecipitates nucleate within the laths in the HDSN1 and HDSN2 steels, while in the case of HDSN3 steel, they do it within the laths, and also on block and prior austenite grain boundaries favored by the absence of $\mathrm{M}_{23} \mathrm{C}_{6}$ carbides at these latter locations.

\subsection{High temperature behavior: Small Punch Creep Tests}

Figure 11 depicts the punch displacement vs. time curves for the HDSN steels. Curves for conventional (G91-AR) and thermomechanically processed (G91-TMT 600_20) G91 steel grade were considered for the sake of comparison. Two specimens of G91-AR were tested to show the reproducibility of the technique. 


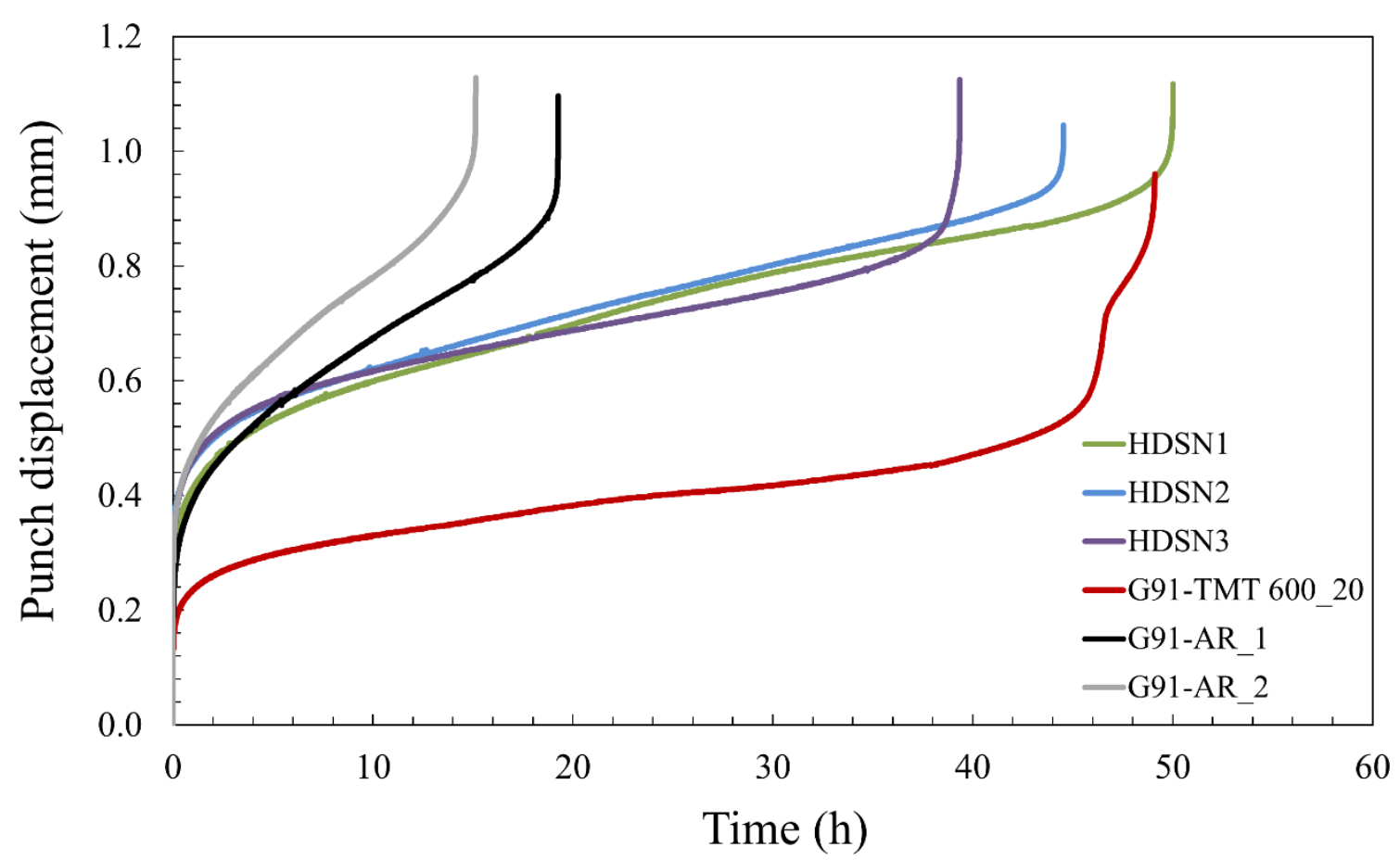

Figure 11. SPCT curves obtained for HDSN, G91-AR and G91-TMT 600_20 steel samples at $700{ }^{\circ} \mathrm{C}$ and $275 \mathrm{~N}$.

The steels labelled as G91-AR (as-received) and G91-TMT 600_20 undergone a conventional heat treatment and a thermomechanical treatment, respectively, were explained by the authors in previous works and are summarized in Table 3 [20, 52].

Table 3. Conventional heat treatment applied to G91-AR and thermomechanical treatment applied to G91-TMT 600_20 steel samples [20, 52].

\begin{tabular}{|c|c|c|c|}
\cline { 2 - 4 } \multicolumn{1}{c|}{} & Austenitization & Ausforming & Tempering \\
\hline G91-AR & $1040^{\circ} \mathrm{C} / 30 \mathrm{~min}$ & - & $730^{\circ} \mathrm{C} / 60 \mathrm{~min}$ \\
\hline G91-TMT 600_20 & $1125^{\circ} \mathrm{C} / 5 \mathrm{~min}$ & $600^{\circ} \mathrm{C} / 20 \%$ & $740^{\circ} \mathrm{C} / 45 \mathrm{~min}$ \\
\hline
\end{tabular}

The microstructural characterization carried out in this work showed that the main differences were the higher number density of MX nanoprecipitates and the larger prior austenite grain size for the G91-TMT 600_20 compared to the microstructure of G91AR. The number density of MX nanoprecipitates was in the order of $10^{22} \mathrm{~m}^{-3}$ for the G91TMT 600_20 while for the G91-AR it was in the order of $10^{19} \mathrm{~m}^{-3}$. Regarding the prior austenite grain size, it varied from $256 \mu \mathrm{m}$ to $43 \mu \mathrm{m}$, for the G91-TMT 600_20 and G91AR, respectively. 
The observation of the different creep stages from the SPCT curves is equivalent to that from conventional uniaxial creep tests. The primary creep stage is defined by a reduction in the deflection rate with time. This decrease continues until the secondary creep stage is reached. In this stage, the deflection rate attains a minimum value. In the final stage, the tertiary creep stage, the deflection rate is accelerated until the rupture of the specimen takes place. In the initial stage, the contact area between the indenter and the specimen increases with time and the bending process is the dominant deformation process. After this, in the secondary creep stage, the deformation process is controlled by the membrane stretching mode where the reduction in thickness dominates the contact area. In the tertiary stage, the localized deformation produces the initiation and propagation of cracks, with the subsequent increase of the disk deflection rate and final rupture of the specimen.

Table 4 shows the results extracted from Figure 11 and allows comparing the high temperature behavior at $700{ }^{\circ} \mathrm{C}$ and $275 \mathrm{~N}$ for the different steels under investigation. There is no significant difference among the HDSN steel and G91-TMT 600_20 steel samples. However, an important decrease in the minimum displacement rate and a great increase in the time to rupture are observed among the HDSN steels compared to those observed for the G91-AR steel samples, which reveal the creep strengthening ability of the new designed steels as compared with the commercial existing ones.

Table 4. SPCT results for the steels under investigation

\begin{tabular}{|c|c|c|}
\cline { 2 - 3 } \multicolumn{1}{c|}{} & $\begin{array}{c}\text { Minimum displacement rate } \\
(\mu \mathrm{m} / \mathrm{h})\end{array}$ & $\begin{array}{c}\text { Time to rupture } \\
(\mathrm{h})\end{array}$ \\
\hline HDSN1 & 5.81 & 50.02 \\
\hline HDSN2 & 7.72 & 44.65 \\
\hline HDSN3 & 6.02 & 39.37 \\
\hline G91-AR_1 & 19.56 & 19.28 \\
\hline G91-AR_2 & 24.05 & 15.15 \\
\hline G91-TMT 600_20 & 2.70 & 49.11 \\
\hline
\end{tabular}

As it has been reported elsewhere [52], the authors concluded that the improved creep strength is achieved by applying a thermomechanical treatment instead of a conventional treatment. This improvement was demonstrated by uniaxial creep tests and was attributable to the higher number density of MX nanoprecipitates [16, 21]. The same high 
temperature strength trend is shown by the small punch creep curves of G91-AR (conventional treatment) and G91-TMT 600_20 (thermomechanical treatment). The minimum displacement rate was reduced down to 9 times and the rupture time was extended up to 3 times for G91-TMT 600_20 compared to G91-AR. HDSN steels exhibited almost the same minimum displacement rate than G91-TMT 600_20. The time to rupture was quite similar among the HDSN and G91-TMT 600_20 steels. The improved high temperature behavior of the HDSN1 and HDSN2 steels compared to the G91-AR steel could be explained in the same sense as for G91-TMT 600_20, i.e. by the high number density of MX nanoprecipitates. The HDSN1 and HDSN2 steels exhibit the same values in terms of number density and size of precipitates than those measured for the G91-TMT 600_20 steel. These MX nanoprecipitates are the most numerous obstacles to dislocation motion and, in consequence, control the recovery of the dislocation substructure. Thus, similar minimum displacement rate might be expected. In the case of the HDSN3 steel, the improvement in high temperature strength cannot be explained just considering the MX distribution within the laths due to the smaller number density of them compared to those measured for the HDSN1 and HDSN2 steels. The improvement in high temperature strength is also justified considering the solid solution strengthening induced by W [53] and the distribution of the MX precipitates on the block, lath and prior austenite grain boundaries. Taneike et al demonstrated in their work [54] that the replacement of $\mathrm{M}_{23} \mathrm{C}_{6}$ carbides by more stable precipitates such as MX nanoprecipitates on lath and block boundaries contributes to increase considerably the creep strength due to the higher thermal stability of these latter precipitates.

It is important to remind that the SPCT duration is very short and only reflects the influence of the initial microstructures produced by the processing route. Iseda et al [55] demonstrated that the dislocation strengthening contributes greatly to extend the time to rupture in short time creep tests. However, this strengthening becomes useless during long-term creep because of the annihilation of dislocations during the recovery and the recrystallization that takes place during the creep test. Nevertheless, Maruyama et al. [56] suggested that a high dislocation density can be useful if the premature recovery of the dislocation substructure is prevented by some means. In the case of the HDSN steels, the approach used to retard the recovery and the recrystallization is by promoting a homogeneous and fine distribution of MX precipitates in the microstructure, which are able to pin the dislocations during creep. Hence, these precipitates would extend the 
strengthening contribution of the dislocations to longer times and, consequently, promote a high creep strength even in long-term creep tests.

Regarding the creep-enhanced thermomechanically processed steels reported elsewhere $[12,52]$, this was accompanied by a low creep ductility induced by the high austenitization temperature necessary to keep all the carbide formers in solid solution prior to the quenching + tempering stages. The coarse prior austenite grain size generated after austenitization produces a change in creep fracture behavior from a transgranular ductile fracture for the conventionally treated steel to an intergranular brittle fracture for the thermomechanically treated steel with the concomitant drop in ductility [57]

Figure 12 shows the SPCT ruptured specimens for all the steels investigated. The rupture occurred at a distance away from the center of the circumference where the concentration of stress/strain is the highest. As it can be seen in Figure 12, the ruptured specimens of the HDSN (Figs. 12a-c) and G91-AR (Fig. 12d) steels show similar reduction in thickness after the test. However, the ruptured specimen of the sample G91-TMT 600_20 (Fig. 12e) shows considerably lesser reduction in thickness with the presence of some radial cracks. This aspect is characteristic of a brittle fracture as it was discussed previously [57]. It is important to point out that the ductility cannot be calculated directly from the maximum displacement obtained on SPCT curves. This value is not representative of the ductility because the punch ball has already gone through the specimen, i.e., the rupture of the specimen has already occurred. 

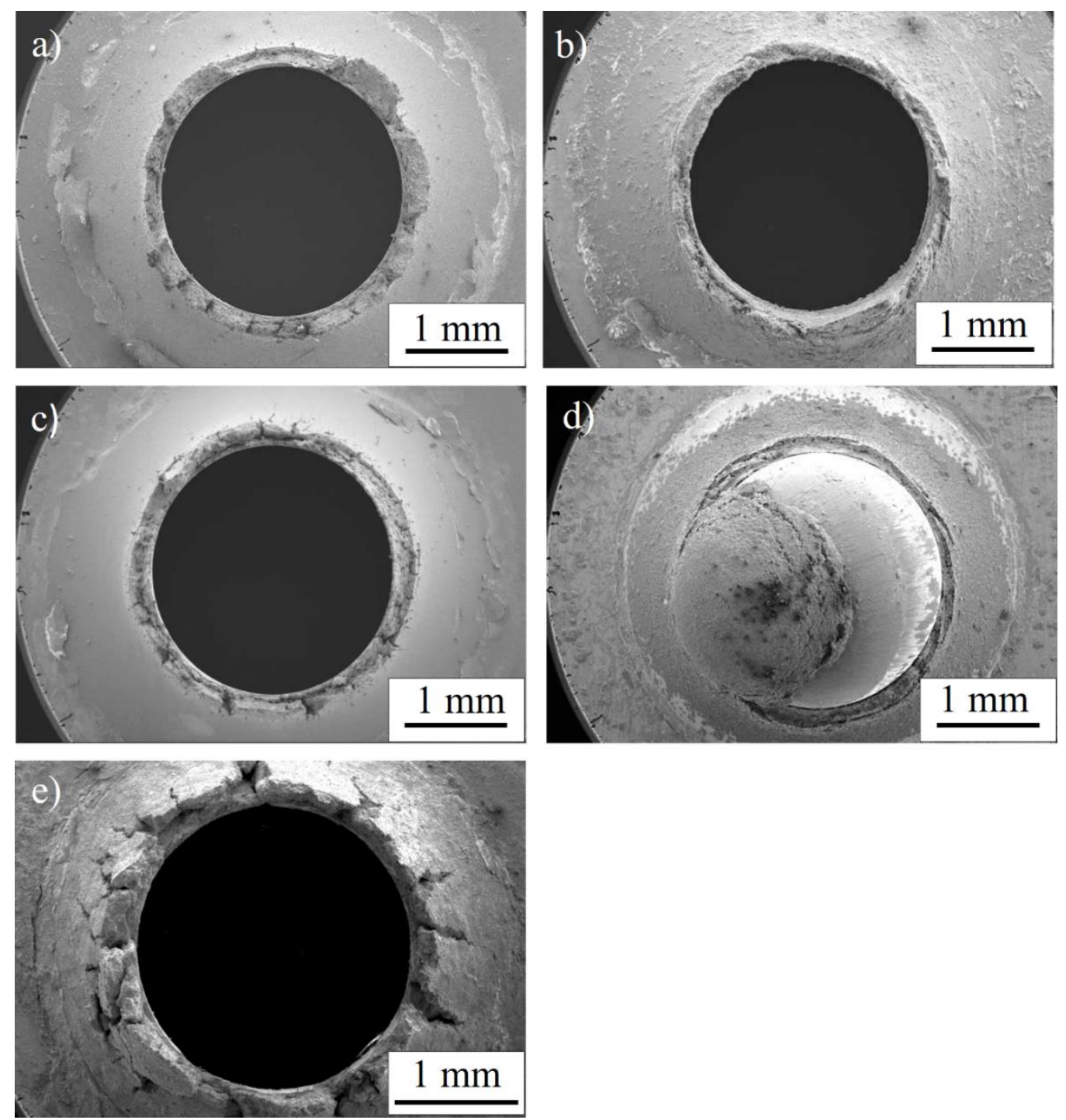

Figure 12. SPCT specimens after rupture for a) HDSN1, b) HDSN2, c) HDSN3, d) G91AR and e) G91-TMT 600_20 steel samples.

Figure 13 shows the fracture surfaces of the HDSN1 (Fig. 13a) and HDSN2 (Fig. 13b) tested specimens. A dimple pattern was identified for both steels, which is characteristic of ductile transgranular fractures. A similar fracture surface was observed by the authors in the G91-AR steel samples after SPCT at $700{ }^{\circ} \mathrm{C}$ using a force of $200 \mathrm{~N}$ [57]. By contrast, a clear cleavage fracture characteristic of brittle microstrutures was observed in the G91-TMT 600_20 steel sample (Fig. 13c). This fracture surface justifies the radial cracks and the low reduction in thickness observed. The ductile fracture mechanism in the HDSN steels is caused by the fine prior austenite grain size resulting from the low austenitization temperature. The austenitization temperature allows preventing an excessive grain growth, which was the main factor that triggered the brittle fracture in the 
thermomechanically treated steels. Along with the temperature effect, the grain growth was inhibited by the grain boundary pinning effect provided by the MX precipitates present during the austenitization (primary carbides).
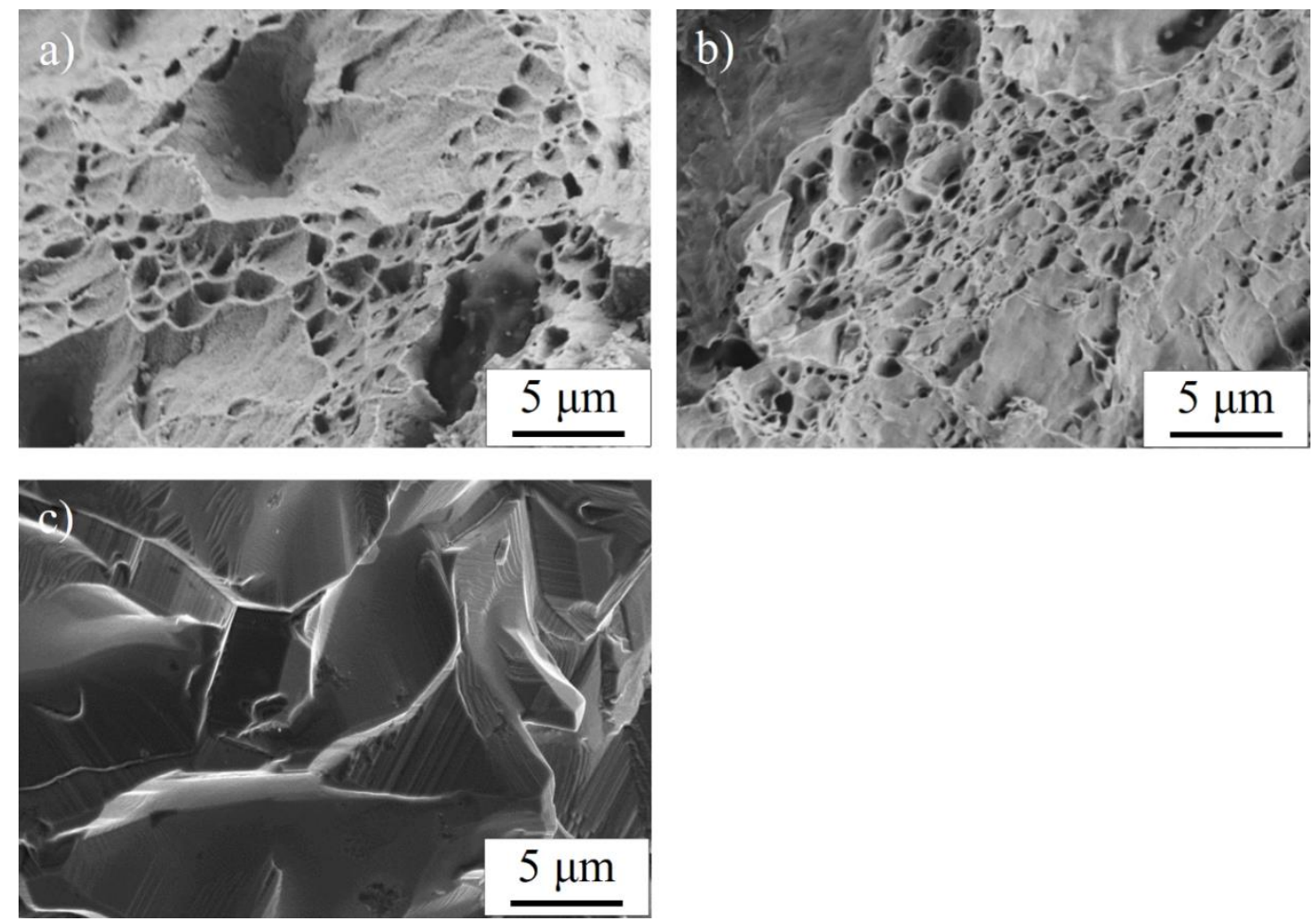

Figure 13. Fractured surfaces for the SPCT specimens for a) HDSN1 b) HDSN2 and c) G91-TMT 600_20 steel samples.

To understand the microstructural degradation process during SPCT in the HDSN steels, EBSD measurements were performed on the specimens after rupture. As it can be seen in Figure 14a) in the IPF map for HDSN2 steel, the martensitic microstructure was modified drastically. The characteristic lath-like shape morphology (Figure 4) has evolved into a microstructure of equiaxed grains, as it can be clearly observed. These equiaxed grains are produced by the recovery and the recrystallization and are preferential areas where the nucleation of cavities occurs as it is pointed out in Figure 14a). These cavities are homogeneously distributed (Figure 14b)) for all the HDSN steels, which is consistent with having a transgranular fracture, as suggested previously. 

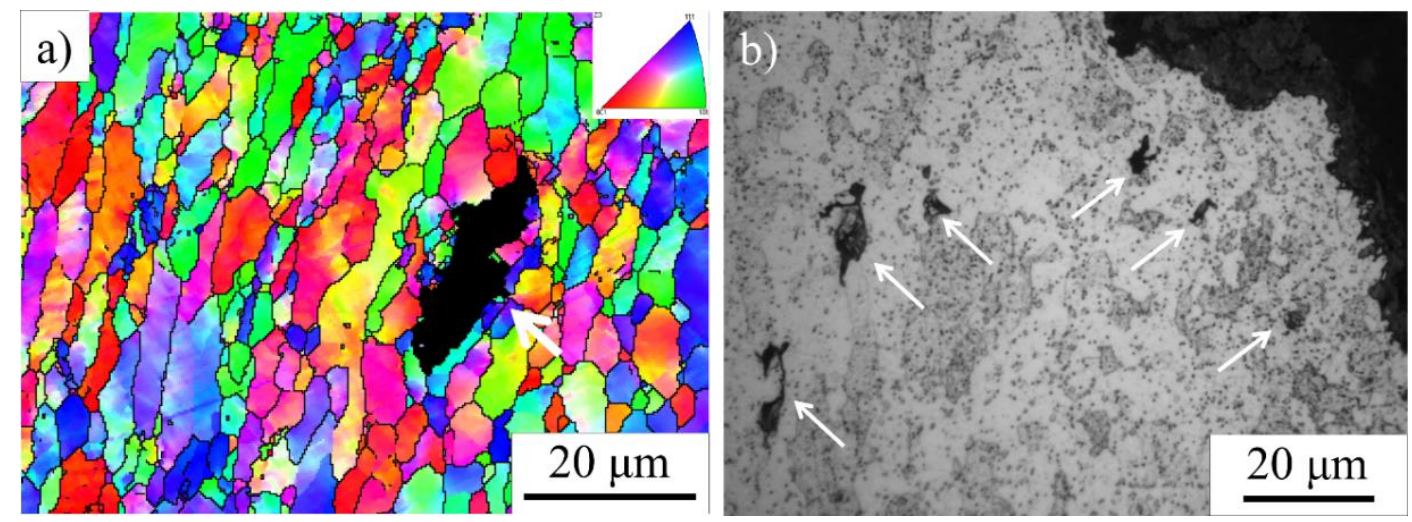

Figure 14. a) IPF and b) optical image for HDSN2 steel after a SPCT. Creep cavities are indicated by white arrows.

Therefore, as a summary, one might conclude that the microstructural degradation during SPCT can be divided into different steps. The first step is the replacement of the characteristic lath-like morphology of martensite by equiaxed ferritic grains. This degradation process might be delayed depending on dislocation pinning provided by the creep strengthening precipitates present in the steel, being key factors their size, number density, thermal stability and location. The second step consists in the nucleation of creep cavities in the weakened regions of the matrix composed of equiaxed grains. Eventually, the third step consists in the coalescence of the cavities to form the cracks that cause the rupture of the specimen.

It is remarkable that the same microstructural degradation process was identified for the G91-AR steel in our previous work [57]. The same degradation process explains the similar high temperature fracture mechanism and the values of ductility obtained for the HDSN steels and for the G91-AR steel sample.

\section{Conclusions}

Novel High Density of Stable Nanoprecipitates (HDSN) steels have been designed to obtain a high density of stable MX nanoprecipitates to improve the creep strength of conventional $9 \mathrm{Cr}$ ferritic/martensitic steels. The amount of MX precipitates was tailored using thermodynamic calculations supported by Thermo-Calc, and designed to be in the range around 0.6-0.85 mol \%, which is considerably higher than the amount (0.4 mol \%) predicted for conventional $9 \mathrm{Cr}$ ferritic/martensitic steels. The microstructural characterization carried out showed up to three orders of magnitude higher number 
density of MX nanoprecipitates within the laths $\left(\sim 10^{22} \mathrm{~m}^{-3}\right)$ for the HDSN steels compared with the G91 steel conventionally heat treated $\left(\sim 10^{19} \mathrm{~m}^{-3}\right)$.

The SPCT undertaken at $700{ }^{\circ} \mathrm{C}$ applying a force of $275 \mathrm{~N}$ was used as screening conditions to evaluate the high temperature strength of the HDSN steels. These steels have demonstrated a remarkable improvement compared with G91 steel. This improvement was attributed to the higher number density of MX nanoprecipitates within the martensitic laths in the HDSN1 and HDSN2 steels. In the case of the HDSN3 steel, the improvement was justified based on the distribution of MX nanoprecipitates within the martensitic laths and on prior austenite grain, martensitic block and martensitic lath boundaries along with the solid solution strengthening provided by the $\mathrm{W}$.

It is worth highlighting that this high temperature strength was quite similar to that obtained for the G91 after the thermomechanical treatment, which owes its high temperature strength to the high number density of MX nanoprecipitates observed within the martensitic laths.

From a post-SPCT analysis it was observed that the HDSN steels possess better ductility compared with the G91 after the thermomechanical treatment and very close to that obtained for the G91 after the conventional treatment. This result implies that HDSN steels overcome the main limitation of the thermomechanical treatment, which is the loss of ductility, offering similar values of high temperature strength.

Finally, the preliminary results shown in this paper allow us to conclude that HDSN steels are promising materials for high temperature applications due to their high temperature strength and appropriate ductility. However, long-term creep tests must be performed in the future to evaluate properly the potential of these novel heat resistant steels.

\section{Acknowledgements}

Authors acknowledge financial support to Spanish Ministerio de Economia y Competitividad (MINECO) in the form of a Coordinate Project (MAT2016-80875-C3-1R). Authors also would like to acknowledge financial support to Comunidad de Madrid through DIMMAT-CM_S2013/MIT-2775 project. J. Vivas acknowledges financial support in the form of a FPI Grant BES-2014-069863. This work contributes to the Joint Programme on Nuclear Materials (JPNM) of the European Energy Research Alliance (EERA). 


\section{Data availability}

The data that support the findings of this study are available from the corresponding author,jvm@cenim.csic.es, upon reasonable request.

\section{References}

[1] R.L. Klueh, D.S. Gelles, S. Jitsukawa, A. Kimura, G.R. Odette, B. van der Schaaf, M. Victoria, Journal of Nuclear Materials, 307-311, Part 1 (2002) 455-465.

[2] S.J. Zinkle, G.S. Was, Acta Materialia, 61 (2013) 735-758.

[3] V. Dudko, A. Belyakov, D. Molodov, R. Kaibyshev, Metallurgical and Materials Transactions A, 44 (2013) 162-172.

[4] M. Mitsuhara, S. Yamasaki, M. Miake, H. Nakashima, M. Nishida, J. Kusumoto, A. Kanaya, Philosophical Magazine Letters, 96 (2016) 76-83.

[5] K. Guguloth, N. Roy, Materials Science and Engineering: A, 680 (2017) 388-404.

[6] B. Xiao, L. Xu, L. Zhao, H. Jing, Y. Han, Z. Tang, Materials Science and Engineering: A, 707 (2017) 466-477.

[7] F. Abe, T. Horiuchi, M. Taneike, K. Sawada, Materials Science and Engineering: A, 378 (2004) 299-303.

[8] F. Abe, M. Taneike, K. Sawada, International Journal of Pressure Vessels and Piping, 84 (2007) 3-12.

[9] F. Abe, Materials Science and Engineering: A, 387 (2004) 565-569.

[10] M. Tamura, H. Sakasegawa, A. Kohyama, H. Esaka, K. Shinozuka, Journal of Nuclear Materials, 321 (2003) 288-293.

[11] L. Tan, T.S. Byun, Y. Katoh, L.L. Snead, Acta Materialia, 71 (2014) 11-19.

[12] J. Vivas, C. Capdevila, E. Altstadt, M. Houska, D. San-Martín, Scripta Materialia, 153 (2018) 14-18.

[13] J. Vivas, C. Celada-Casero, D. San Martín, M. Serrano, E. Urones-Garrote, P. Adeva, M.M. Aranda, C. Capdevila, Metallurgical and Materials Transactions A, (2016) $1-8$.

[14] R. Hernandez, M. Serrano, A. Garcia-Junceda, E. Onorbe, J. Vivas, ASME 2019 Pressure Vessels and Piping Conference, PVP 2019, American Society of Mechanical Engineers (ASME), 2019. 
[15] S. Hollner, B. Fournier, J. Le Pendu, T. Cozzika, I. Tournié, J.C. Brachet, A. Pineau, Journal of Nuclear Materials, 405 (2010) 101-108.

[16] R.L. Klueh, N. Hashimoto, P.J. Maziasz, Journal of Nuclear Materials, 367-370, Part A (2007) 48-53.

[17] L. Tan, J.T. Busby, P.J. Maziasz, Y. Yamamoto, Journal of Nuclear Materials, 441 (2013) 713-717.

[18] J. Vivas, D. De-Castro, J.D. Poplawsky, D. San-Martín, C. Capdevila, Scripta Materialia, 164 (2019) 76-81.

[19] J. Hoffmann, M. Rieth, L. Commin, P. Fernández, M. Roldán, Nuclear Materials and Energy, 6 (2016) 12-17.

[20] J. Vivas, C. Capdevila, J. Jimenez, M. Benito-Alfonso, D. San-Martin, Metals, 7 (2017) 236.

[21] R.L. Klueh, N. Hashimoto, P.J. Maziasz, Scripta Materialia, 53 (2005) 275-280.

[22] L. Tan, Y. Katoh, L.L. Snead, Journal of Nuclear Materials, 511 (2018) 598-604.

[23] L. Tan, L.L. Snead, Y. Katoh, Journal of Nuclear Materials, 478 (2016) 42-49.

[24] E. Altstadt, H.E. Ge, V. Kuksenko, M. Serrano, M. Houska, M. Lasan, M.

Bruchhausen, J.M. Lapetite, Y. Dai, Journal of Nuclear Materials, 472 (2016) 186-195.

[25] E. Altstadt, M. Serrano, M. Houska, A. García-Junceda, Mater. Sci. Eng. A, 654 (2016) 309-316.

[26] B. Kim, B. Lim, Acta Mech. Solida Sin., 21 (2008) 312-317.

[27] S. Yang, Y. Zheng, X. Ling, Eng. Fail. Anal., 91 (2018) 99-107.

[28] F. Dobeš, K. Milička, Materials Science and Engineering: A, 510-511 (2009) 440443.

[29] G.S. Deshmukh, M.L. Prasad, D.R. Peshwe, J.G. Kumar, M.D. Mathew, G. Amarendra, Transactions of the Indian Institute of Metals, 69 (2016) 907-915. [30] Naveena, S.-i. Komazaki, Materials Science and Engineering: A, 676 (2016) 100108.

[31] A. Ortiz-Mariscal, M.L. Saucedo-Muñoz, Naveena, S. Komazaki, Materials Science and Engineering: A, 709 (2018) 322-329.

[32] S. Yang, X. Ling, Y. Zheng, R. Ma, Mater. Des., 91 (2016) 98-103.

[33] L. Zhao, H. Jing, L. Xu, Y. Han, J. Xiu, Y. Qiao, Materials \& Design, 47 (2013) 677-686.

[34] J.P. Rouse, F. Cortellino, W. Sun, T.H. Hyde, J. Shingledecker, Mater. Sci. Technol., 29 (2013) 1328-1345. 
[35] L. Zhao, K. Song, L. Xu, Y. Han, H. Jing, Y. Zhang, H. Li, Theor. Appl. Fract. Mech., 104 (2019).

[36] F. Masuyama, ISIJ International, 41 (2001) 612-625.

[37] F. Abe, Materials Science and Engineering: A, 319-321 (2001) 770-773.

[38] X. Wang, Q. Xu, S.-m. Yu, L. Hu, H. Liu, Y.-y. Ren, Materials Chemistry and Physics, 163 (2015) 219-228.

[39] X.Z. Zhang, X.J. Wu, R. Liu, J. Liu, M.X. Yao, Materials Science and Engineering: A, 706 (2017) 279-286.

[40] K. Sawada, M. Takeda, K. Maruyama, R. Ishii, M. Yamada, Y. Nagae, R. Komine, Materials Science and Engineering: A, 267 (1999) 19-25.

[41] P. Hu, W. Yan, L.-f. Deng, W. Sha, Y.-y. Shan, K. Yang, Fusion Engineering and Design, 85 (2010) 1632-1637.

[42] P. Wang, J. Chen, H. Fu, S. Liu, X. Li, Z. Xu, Journal of Nuclear Materials, 442 (2013) S9-S12.

[43] T. Hasegawa, Y. Tomita, A. Kohyama, Journal of Nuclear Materials, 258-263, Part 2 (1998) 1153-1157.

[44] W.B. Liu, C. Zhang, Z.X. Xia, Z.G. Yang, Journal of Nuclear Materials, 455 (2014) 402-406.

[45] L. Helis, Y. Toda, T. Hara, H. Miyazaki, F. Abe, Materials Science and Engineering: A, 510-511 (2009) 88-94.

[46] A. Kipelova, R. Kaibyshev, A. Belyakov, D. Molodov, Materials Science and Engineering: A, 528 (2011) 1280-1286.

[47] L. Cipolla, H.K. Danielsen, D. Venditti, P.E. Di Nunzio, J. Hald, M.A.J. Somers, Acta Materialia, 58 (2010) 669-679.

[48] K. Sawada, M. Tabuchi, H. Hongo, T. Watanabe, K. Kimura, Materials Characterization, 59 (2008) 1161-1167.

[49] H.K. Danielsen, J. Hald, Materials Science and Engineering: A, 505 (2009) 169177.

[50] P. Yan, Z. Liu, H. Bao, Y. Weng, W. Liu, Materials Science and Engineering: A, 588 (2013) 22-28.

[51] N. Saini, R.S. Mulik, M.M. Mahapatra, Materials Science and Engineering: A, 716 (2018) 179-188.

[52] J. Vivas, C. Capdevila, E. Altstadt, M. Houska, M. Serrano, D. De-Castro, D. SanMartín, Materials Science and Engineering: A, 728 (2018) 259-265. 
[53] A. Fedoseeva, N. Dudova, R. Kaibyshev, A. Belyakov, Metals, 7 (2017) 573.

[54] M. Taneike, K. Sawada, F. Abe, Metallurgical and Materials Transactions A, 35 (2004) 1255-1262.

[55] A. Iseda, H. Teranishi, F. Masuyama, Tetsu To Hagane, 76 (1990) 1076-1083.

[56] K. Maruyama, K. Sawada, J.I. Koike, ISIJ International, 41 (2001) 641-653.

[57] J. Vivas, C. Capdevila, E. Altstadt, M. Houska, I. Sabirov, D. San-Martín, Metals and Materials International, 25 (2019) 343-352. 